\title{
ULTRA-HIGH-PERFORMANCE FIBRE-REINFORCED CONCRETE UNDER HIGH-VELOCITY PROJECTILE IMPACT. PART II. APPLICABILITY OF PREDICTION MODELS
}

\author{
Sebastjan Kravanja ${ }^{a}$, Radoslav Sovják ${ }^{b, *}$ \\ ${ }^{a}$ Faculty of Civil and Geodetic Engineering, University of Ljubljana, Jamova cesta 2, Ljubljana 1000, Slovenia \\ ${ }^{b}$ Faculty of Civil Engineering, Czech Technical University in Prague, Thákurova 7, 166 29 Prague 6, Czech \\ Republic \\ * corresponding author: sovjak@fsv.cvut.cz
}

\begin{abstract}
Semi-infinite targets of Ultra-High-Performance Fibre-Reinforced Concrete with various fibre volume fractions were subjected to the high-velocity projectile impact using in-service bullets. In this study, a variety of empirical and semi-analytical models for prediction of the depth of penetration and mass ejection were evaluated with respect to the experimental results. Models for the depth of penetration and spalling mass ejection were revisited and applied both with deformable and nondeformable projectiles parameters. The applicability of the prediction models was assessed through a statistical comparison of values from models with experimental results. The evaluation of the applicability was made through the newly proposed measure of a relative prediction accuracy for model selection and model estimation, which was verified with established statistical accuracy evaluations, such as accuracy ratio, logarithmic standard deviation and correlation coefficient. The best fit to the experimental readings was provided by newer semi-analytical models, which are incorporating additional concrete parameters beside compressive strength while the majority of older models failed to provide sufficient accuracy.
\end{abstract}

KEYWORDS: projectile impact; UHPFRC; prediction models; depth of penetration; mass ejection.

\section{INTRODUCTION}

A set of results for Ultra-High-Performance FibreReinforced Concrete (UHPFRC) with various fibre volume fractions under a high-velocity projectile impact was gathered for both rigid (non-deformable) and soft (deformable) projectile [1]. The UHPFRC was chosen due to its exceptional mechanical properties and impact resistance. In the framework of this study, UHPFRCs with unconfined compressive strengths over $110 \mathrm{MPa}$ were reinforced with discrete steel fibres in five different volumetric fractions ranging from $0.125 \%$ to $2.0 \%$, while additional control specimens without fibre inclusion (i.e., 0\%, plain UHPC) were tested as well.

The rigid projectile was provided by a bullet with a full-metal jacket and mild-steel core (FMJ-MSC or MSC) while the soft projectile was provided by a bullet with a full-metal jacket and soft-lead core (FMJ-SLC or SLC). Both projectiles were chosen because they represent a world's widespread intermediate cartridge for the military assault rifle AK-47.

For semi-infinite targets investigated in this study, loaded with high-velocity projectile impact, a number of empirical and semi-analytical prediction models for predicting the penetration depth and mass ejection were tested and evaluated through comparison to the experimental results. Predicting the effect of the projectile impact on cementitious composite is a very complex problem and although empirical formulas do exist, most accurate methods are semi-analytical models and numerical simulations. Empirical formulas are based on the coefficients calibration and fitting of the empirical constants and do not contain any physical substance, while semi-analytical models are developed on the basis of a physical concept and then calibrated to experimental results. A large number of predictive models were used and its applicability for the case of this study was evaluated and discussed.

\section{TheORETICAL BACKGROUND}

Throughout modern history, numerous empirical and semi-analytical prediction models have been developed and tested for the means of calculating the prediction of the penetration depth due to projectile impact on solid materials. The purpose was to verify if any of the existent penetration models fit the results gathered from the experimental part of this study. By this means, in total 42 penetration depth prediction models, which were publicly accessible, were evaluated and their results were compared with the results of the experimental analysis and between each other. The accuracy of the prediction models was evaluated with the use of value forecast model accuracy assessment $\sum \ln ^{2} Q$ proposed by Tofallis 2, for which it was proven to be less biased than other known statistical 
assessments and can be calculated using

$$
\sum \ln ^{2} Q=\sum_{i=1}^{n} \ln ^{2} Q_{i},
$$

where $Q_{i}$ is named accuracy ratio and is calculated as

$$
Q_{i}=\frac{F_{\mathrm{t}}}{A_{\mathrm{t}}}
$$

where $F_{\mathrm{t}}$ is predicted (forecast) value and $A_{\mathrm{t}}$ is the actual value of the compared quantity. In this case, the predicted value represented the result from prediction models (whether it was penetration depth or mass ejection) and the actual value represented the result from the experimental investigation. The model and experimental results were gathered for each of the six different fibre volumetric ratios (including the plain UHPC mixture), so the summation index i of the square of logarithmic values of accuracy ratios is assuming values from 1 to 6 . Higher accuracy of the prediction models results in a lower value from the accuracy assessment equation; therefore, the most accurate models had the lowest accuracy estimation values. The efficiency of the newly proposed logarithmic assessment by Tofallis was verified by using much more established logarithmic standard deviation (LSD), which is calculated by the equation

$$
L S D=\sqrt{\frac{\sum\left(s^{2} / 2-\ln ^{2} Q_{i}\right)}{n-1}},
$$

where $s^{2}$ is the sample variance of the accuracy ratio $Q_{i}$. In this assessment, the lower value means lower error and higher accuracy of the prediction model. In addition, the statistical quantity of the correlation coefficient was calculated for each model with respect to the experimental results in order to evaluate the relative relation between these values 3 .

In the vast majority of the cases of penetration models, the unconfined compressive strength of a concrete target is a major parameter on the resistance side of the model. The major supposition in the development of prediction models was that the penetration depth and crater volume are in inverse correlation to the unconfined compressive strength of the concrete. However, Kennedy [4] proposed, according to the one-dimensional theory of wave propagation, that significant reflected tensile wave also appears in the target with finite geometries. The tensile strength affects the spalling and scabbing part, and therefore cannot be neglected. This was appropriately incorporated in the newly proposed semi-analytical model by Hwang et al. [5].

\subsection{PARAmeters.}

It is important to mention that the majority of the empirical and semi-analytical models with empirical factors were developed through the curve fitting and

\begin{tabular}{|c|c|c|}
\hline Symbol & Parameter & Unit \\
\hline \multicolumn{3}{|c|}{ Impact parameters } \\
\hline$X$ & Predicted penetration depth & $\mathrm{m}$ \\
\hline$v_{i}$ & Projectile impact velocity & $\mathrm{m} / \mathrm{s}$ \\
\hline$D$ & Diameter of the projectile & $\mathrm{m}$ \\
\hline$M$ & Mass of the projectile & $\mathrm{kg}$ \\
\hline$C R H$ & Calibre Radius Head & - \\
\hline$N^{*}$ & Nose shape factor & - \\
\hline$\rho_{\mathrm{p}}$ & $\begin{array}{l}\text { Density of the projectile } \\
\text { core material }\end{array}$ & $\mathrm{kg} / \mathrm{m}^{3}$ \\
\hline$E_{\mathrm{p}}$ & $\begin{array}{l}\text { Elastic modulus of the } \\
\text { projectile core material }\end{array}$ & $\mathrm{Pa}$ \\
\hline$Y_{\mathrm{p}}$ & $\begin{array}{l}\text { Yield strength of the projectile } \\
\text { core material }\end{array}$ & $\mathrm{Pa}$ \\
\hline \multicolumn{3}{|c|}{ Concrete target parameters } \\
\hline$f_{\mathrm{c}}^{\prime}$ & $\begin{array}{l}\text { Unconfined compressive } \\
\text { strength }\end{array}$ & $\mathrm{Pa}$ \\
\hline$\rho_{\mathrm{c}}$ & Density & $\mathrm{kg} / \mathrm{m}^{3}$ \\
\hline$f_{\mathrm{t}}$ & Direct tensile strength & $\mathrm{Pa}$ \\
\hline$p$ & Fibre volumetric fraction & $\%$ \\
\hline$s_{\mathrm{a}}$ & $\begin{array}{l}\text { Maximum diameter } \\
\text { of coarse aggregate }\end{array}$ & $\mathrm{m}$ \\
\hline$h$ & Target thickness & $\mathrm{m}$ \\
\hline
\end{tabular}
regression analysis on the basis of experimental results, therefore establishing a strict application range
TABLE 1. Parameters used in prediction models.

of validity 6 . The application range is a set of intervals of parameters, for which the models have been tested, proven or for which the empirical factors were calculated. In the majority of models, these parameters are mass, diameter and impact velocity of the projectile and unconfined compressive strength of the concrete target.

In penetration and mass ejection prediction models, a various set of parameters can be used. The parameters are divided into two parts: impact parameters, which are considering the projectile physical properties as well as impact velocity or impact kinetic energy, and target parameters, which are considering physical properties of the concrete target (Table 1).

\section{The DePTH OF PENETRATION FOR NON-DEFORMABLE PROJECTILES}

Five of the most known models and newest models, which were used in the study, are briefly described in this chapter. The original equation of the National Defence Research Committee (NDRC) was presented in 1946 and was based on the physical model of the impact process [7]. In this model, the force on the projectile is assumed to increase linearly to a penetration depth of $x=2 d$ and further on remains at a constant value. Later, it has been shown that this model does not give an appropriate description of the penetration process, however, it was further modified to calculate total penetration depth with respect to the boundary condition of $x=2 d$. The penetration 
model consisted of impact parameters of projectile velocity, diameter and mass, and additional empirical factors of material dependence and the nose shape factor. The latter two were later determined and a first modified NDRC formula was developed through the definition of the impact function $G$. In 1978, Kar 7 ] revised the NDRC formula to consider the type of the projectile material using a regression analysis. The type of the material was incorporated through the use of the ratio between Young's elastic modulus of the deformable projectile material and the referenced elastic modulus of steel, and the modified impact function was proposed [8. In 2012, Almusallam 9] proposed and further modified the NDRC equation to incorporate the effect of the fibre reinforcement in the concrete matrix. An exponential term was introduced to the impact function $G$ while the general form of the NDRC equation remained unaltered. In 2015, the authors proposed the equation for calculating fibre empirical constants, based on fibre's geometrical and mechanical properties [9, 10].

\section{Hwang et Al. PREDiCtion model}

A new model for prediction of the penetration depth was presented by Hwang et al. [5]. The whole model is based on the principle of the energy conservation law, in which the authors are considering two main energies, which appear at the impact process: kinetic energy of the projectile $E_{\mathrm{K}}$ and resistant energy of the concrete target $E_{\mathrm{R}}$. The latter is further divided into three resistant energies, which appear in the target of finite geometries: spalling $E_{\mathrm{S}}$, tunnelling $E_{\mathrm{T}}$ and scabbing $E_{\mathrm{C}}$ resistant energy. We have:

$$
\begin{gathered}
E_{\mathrm{K}}=\frac{m}{2}\left(v_{i}^{2}-v_{\mathrm{r}}^{2}\right), \\
E_{\mathrm{R}}=E_{\mathrm{S}}+E_{\mathrm{T}}+E_{\mathrm{C}} .
\end{gathered}
$$

With respect to the energy conservation law, the kinetic energy $E_{\mathrm{K}}$ on the influence (impact) side of the problem is the same as the mobilized resistant energy $E_{\mathrm{R}}$ of the concrete target.

In the continuation, a brief summary of the energy model calculation is presented. The original model is entirely the work of the authors of this model $[5]$ and is presented just with the intention of explaining its basic assumptions.

\subsection{SPAlling RESistant ENERGy}

The spalling energy is dissipated due to the reflected impact force (reflected tension wave) on the proximal face of the target. The dissipation of the energy emerges as an ejection of a concrete part, which is idealized with the truncated cone. The resistance force $F_{\mathrm{S}}$ of the concrete cone is defined as

$$
F_{\mathrm{S}}=f_{\mathrm{td}}\left(t_{\mathrm{s}} b_{\mathrm{s}} \tan \theta_{\mathrm{s}}+\frac{\pi d^{2}}{4}\right) k_{\mathrm{s}} k_{\mathrm{bs}}
$$

where $f_{\mathrm{td}}$ is the concrete tensile strength increased by the strain rate according to the fib Model code
2010 [11; $t_{\mathrm{s}}$ is the allowable spalling depth; $\theta_{\mathrm{s}}$ is the average failure cone angle; $b_{\mathrm{s}}$ is the average perimeter of the concrete cone; $k_{\mathrm{S}}$ is the size effect factor and $k_{\mathrm{bs}}$ is the stress concentration factor. The proposed formula for the average perimeter of the concrete cone $b_{\mathrm{s}}$ with a diameter of $d+2 t_{\mathrm{s}} \tan \theta_{\mathrm{s}}$ was corrected from $b_{\mathrm{s}}=\pi\left(d+t_{\mathrm{s}} \tan \theta_{\mathrm{s}}\right)$ to $b_{\mathrm{s}}=\pi\left(d+2 t_{\mathrm{s}} \tan \theta_{\mathrm{s}}\right)$ by the reason of the inferred error in the text, however, it was used only in the modified version of the model.

Allowable spalling depth is the maximal depth of the ejected concrete cone. The model is proposing an estimation of the allowable spalling depth using four empirical factors, which take into consideration concrete target's thickness, steel fibre volumetric ratio, concrete's density and maximum size of the coarse aggregate. The average tangent value of an idealized cone angle was proposed by the authors of the model, which was experimentally acquired through larger series of experimental data. For an ogive nose projectile, it was proposed to be 1.55 , which corresponds to a cone failure angle of $57.17^{\circ}$.

The expression of the resistance force $F_{\mathrm{S}}$ is multiplying the designed concrete tensile strength with truncated cone surface area (without bottom surface area on the face of the specimen). It is then multiplied by the size effect factor, which is determined by the concrete target's thickness and stress concentration factor, which is an empirical factor proposed to a value 1.25 by authors. The non-conventional term for the cone surface area was not in a good agreement with experimental results of the crater cone area and it gave underestimated results and was, therefore, replaced with the conventional geometrical equation for a lateral cone surface area $A_{1}$ :

$$
A_{1}=\pi\left(r_{1}+r_{2}\right) \sqrt{\left(r_{1}-r_{2}\right)^{2}+t_{\mathrm{s}}^{2}},
$$

where

$$
r_{1}=\frac{d+2 t_{\mathrm{s}} \tan \theta_{\mathrm{s}}}{2}, \quad r_{2}=\frac{d}{2}
$$

are the radii of the bottom and top circle surfaces, respectively, and $t_{\mathrm{s}}$ is the originally proposed allowable spalling depth.

The resistance force $F_{\mathrm{S}}$ was then calculated by the modified expression

$$
F_{\mathrm{S}}=\left(A_{\mathrm{l}}+\frac{\pi d^{2}}{4}\right) f_{\mathrm{td}} k_{\mathrm{s}} k_{\mathrm{bs}}
$$

The spalling resistant energy could then be determined by the equation

$$
E_{\mathrm{S}}=F_{\mathrm{S}} \frac{V_{\mathrm{SC}}}{A_{\mathrm{SP}}}
$$

where $V_{\mathrm{SC}}$ is the volume of an idealized concrete cone and $A_{\mathrm{SP}}$ is the projected area of the idealized concrete cone on the proximal face of the target. Both of these estimated quantities could also be compared with measured values. 


\subsection{TUNnELling RESISTANT ENERGY}

After the spalling region, the projectile continues its way through the concrete material by a tight tunnelling penetration. The projectile velocity is decreased by the bond resistance between the projectile and concrete. The authors of the model suggest the following expression for the bond resistance

$$
F_{\mathrm{t}}=\pi d t_{\mathrm{t}} \psi \tau_{\mathrm{d}}
$$

where $t_{\mathrm{t}}$ is the allowable tunnelling depth, $\psi$ is the nose shape factor ( 0.7 for ogive nosed) and $\tau_{\mathrm{d}}$ is the bond strength, increased by a strain effect depending on the strain rate affecting the compressive strength according to the fib Model code 2010 [11]. The tunnelling resistant energy could then be calculated with the equation

$$
E_{\mathrm{T}}=\frac{F_{\mathrm{t}}}{\rho_{\mathrm{p}} A_{\mathrm{p}}} m .
$$

\subsection{SCABBing RESISTANT ENERGY}

The scabbing failure mode is, according to the authors, similar to the spalling failure mode, and therefore uses the same method for the resistant energy calculation. An allowable scabbing depth $t_{\mathrm{c}}$ is assumed to be equal to the allowable spalling depth, while the average tangent value of an idealized failure cone angle on the scabbing part is proposed to be 2.0, regardless of the projectile nose shape.

In addition, also in a part of the scabbing resistance energy calculation, the lateral area of the cone was replaced with the equation, which was presented in the spalling resistant energy section. The energy model with modified expressions for the lateral area of the concrete cone in both spalling and scabbing resistance energy section and corrected equation for the crater perimeter was labelled as Mod. Hwang et al.

\subsection{Penetration Depth CAlculation}

The total penetration depth $(x)$ was calculated by an equation that is derived on the basis of the aforementioned assumptions [5] for targets with semi-infinite geometries, where perforation does not occur, as

$$
x=\frac{m v_{i}^{2}}{2 E_{\mathrm{R}, \max }}\left(h-t_{\mathrm{s}}\right) .
$$

Both the models, one with exact original formulas (Hwang et al.) and one with two modified expressions for the spalling and scabbing crater perimeters and failure cone lateral area (Mod. Hwang et al.) were compared with the data from the experimental study.

\section{The DEPTH OF PENETRATION FOR DEFORMABLE PROJECTILES}

An analytical algebraic formula for the penetration prediction of a deformable projectile impact into a deformable target material was proposed by Rubin and Yarin [12]. It is divided into two stages of penetration: first, a deformable penetration stage and second, a rigid penetration stage. In the first stage of the penetration $P_{\mathrm{I}}$, the projectile's head deforms into a mushroom-like shape and its tail remains rigid - a projectile is eroding with its length decreasing while the penetration velocity is relatively constant. It is assumed by the authors that after the first stage, the remaining mushroom-like head and rigid tail continue to penetrate the target as a rigid body - the second stage $P_{\text {II }}$ begins. The total penetration $x$ is calculated by summarizing the penetration depths from both stages $x=P_{\mathrm{I}}+P_{\mathrm{II}}$.

The first stage penetration depth $P_{\mathrm{I}}$ can be calculated with the use of the following formulas:

$$
\begin{gathered}
P_{\mathrm{I}}=\frac{u}{v_{i}-u} L_{\mathrm{er}} \\
L_{\mathrm{er}}=\left(L_{0}-l_{0}\right)\left(1-\exp \frac{-\rho_{\mathrm{p}}\left(v_{i}-u\right)^{2}}{2 Y_{\mathrm{p}}}\right),
\end{gathered}
$$

where $u$ is the decreased velocity of the projectile due to the pressure at the target/projectile interface, calculated with the use of the projectile and target densities and assumed as constant, $L_{\mathrm{er}}$ is the length of the portion of the rigid tail of the projectile that has been eroded away, $L_{0}$ is the initial projectile length and $l_{0}$ is the length of the mushroom-like section.

The model is derived for the penetration of the cylindrical rod with an initial length $L_{0}$. The analytical formula only considers cylinder-shaped blunt-nosed projectile. In this study, the head of the projectile was not blunt. However, since the resulting values of this analytical model are strongly influenced by the projectile length, an assumption of the equivalent length of the idealized cylindrical projectile was made and used in the equation. The equivalent length of the lead core was calculated by calculating the actual total volume of the core (by the cylinder and truncated cone) and then dividing it by the actual area of a cylindrical part of the deformable projectile core with a diameter of $6.32 \mathrm{~mm}$, yielding an equivalent length $L_{0}=13.81 \mathrm{~mm}$, which was further used in this model.

Although the resulting values of the Rubin and Yarin analytical model are strongly influenced by the projectile length, the effect of the nose shape for a deformable projectile should also be noted. Walker and Anderson [13] reported that the conical nosed projectiles did not perform as well as the blunt-nosed projectiles when the target was sufficiently hard to cause a significant projectile erosion. It can be derived that the deformable ogive-nosed projectile used in this study, which undergone a significant erosion, possibly induces a smaller damage than a blunt-nosed projectile. Results from the analytical model should be, therefore, on the safe side. Again, it is important to mention that an equivalent length was established with an assumption that the major part of the cratering damage is governed by the length of the projectile. 


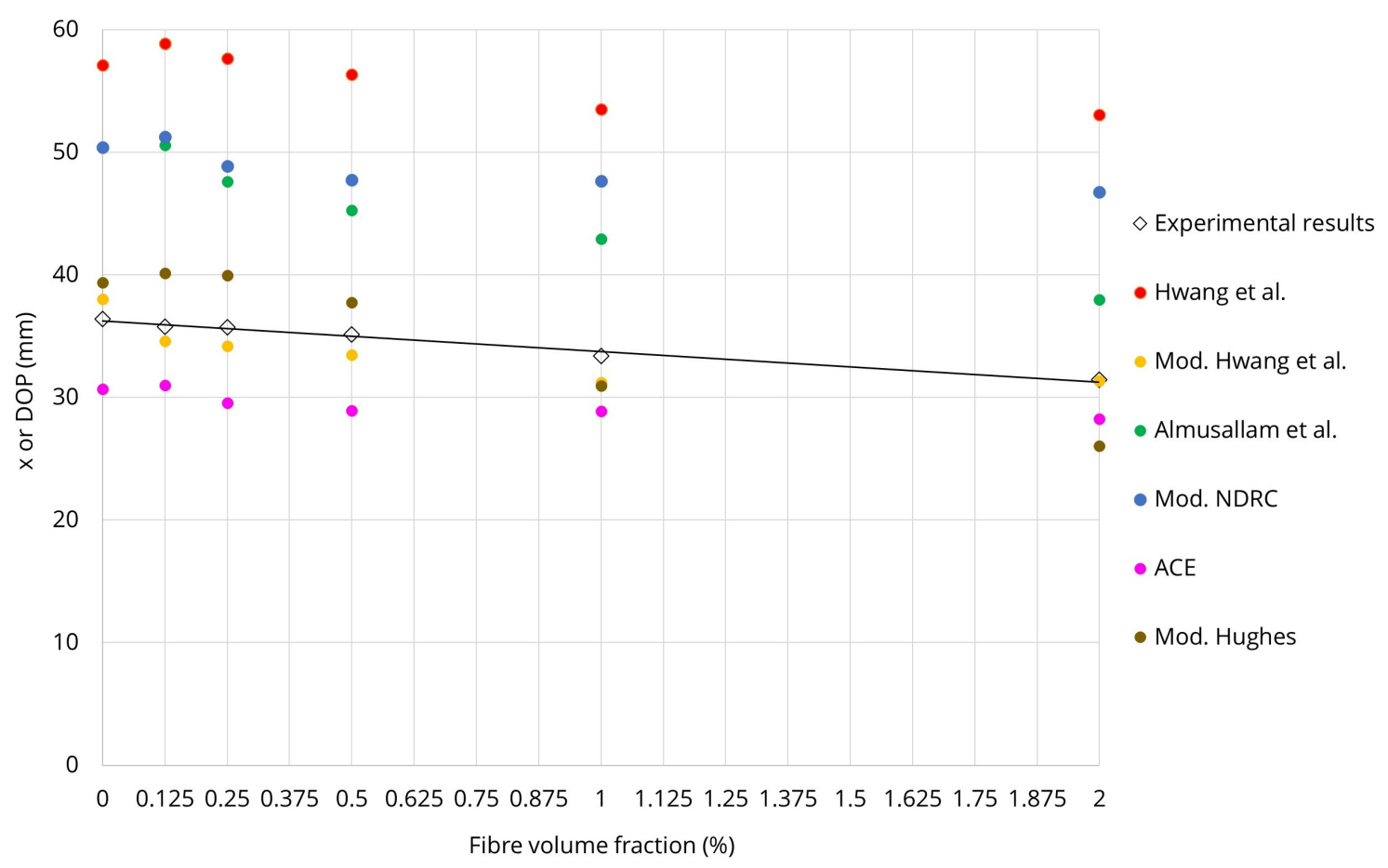

FiguRE 1. Comparison between experimental and representative prediction model results for DOP for non-deformable FMJ-MSC projectile impact on UHPFRC and linear regression line for experimental data.

\section{SPALLing MASS EJECTION}

For the mass ejection prediction, two models were found accessible in public literature and assessed with corresponding input data. The model of Sierakowski [14] is based on the physical principle of impulse. It is calculated by integrating resultant force with respect to time; however, in the case of an object of a constant mass (rigid projectile), the impulse can be expressed as a difference in momentum. The major supposition in this empirical model is that the volume of the impact crater is in inverse correlation with the square root of the unconfined compressive strength of the concrete. A prediction for the ejected mass from the front and the rear faces of fibre reinforced concrete slabs subjected to impact loads was proposed by Almusallam [15]. The mass defragmented from the front face was modelled by a combination of a crater and a tunnel in a manner similar to the one in the prediction model by Hwang et al., however, the shape of the front face crater at the proximal face was assumed to be elliptical and the shape of the crater at the penetration depth was assumed to be circular, whereas the transition was considered to be elliptical. The authors also proposed prediction equations for this quantity [16, which yielded a suitable usability of the prediction model in terms of designing of structures. The prediction model for equivalent crater diameter is incorporating the fibre effect directly through the use of the reinforcing index, whereas the prediction model for total mass ejection is incorporating this effect through the use of a penetration depth by Almusallam et al. modified NDRC, equivalent crater diameter and additional tunnelling depth.

\begin{tabular}{lcc}
\hline & FMJ-MSC & FMJ-SLC \\
\hline Modulus of elasticity & 210 & 44.3 \\
$\quad E_{\mathrm{p}}(\mathrm{GPa})$ & & \\
Density $\rho_{\mathrm{p}}\left(\mathrm{kg} / \mathrm{m}^{3}\right)$ & 7850 & 10735 \\
Yield strength $Y_{\mathrm{p}}(\mathrm{MPa})$ & 552 & 73.3 \\
\hline
\end{tabular}

TABLE 2. Assessed input parameters regarding projectile's core material properties for consideration of deformability in prediction models.

\section{RESUlts FOR DEPTH OF PENETRATION}

In total, 42 prediction models were tested for the prediction of the penetration depth. The projectile core diameter was used in the calculation in both the MSC and SLC cases.

In the prediction models for the deformable projectile penetration, the projectile deformability is incorporated through the use of ratios of the modulus of elasticity, density or yield strength of the projectile's core and steel (Table2).

\subsection{Non-DEFormable FMJ-MSC PROJECTILE}

The results gathered through a calculation of prediction models of rigid projectile penetration gave values with a large dispersion. For better clarity, the prediction models, which take into account the fibre incorporation and/or high strain rate effect, were plotted (Figure 1). Additionally, original modified NDRC and $\mathrm{ACE}$ equations were added for their common and 


\begin{tabular}{|c|c|c|c|c|c|c|}
\hline $\begin{array}{l}\text { Acc. } \\
\text { scale }\end{array}$ & Model & Ref. & $\sum \ln ^{2} Q$ & $\overline{Q_{i}}$ & $L S D$ & $\rho_{\mathrm{FA}}$ \\
\hline 1 & Mod. Hwang et al.* & 5 & 0.012 & 0.98 & 0.049 & 0.841 \\
\hline 2 & Haldar-Hamieh & 8, 17 & 0.057 & 1.1 & 0.105 & 0.82 \\
\hline 3 & Mod. Hughes* & [8, 18 & 0.078 & 1.03 & 0.124 & 0.983 \\
\hline 4 & Haldar \& Miller & 77, 19 & 0.147 & 0.86 & 0.172 & 0.82 \\
\hline 5 & $\mathrm{ACE}$ & {$[4,8$} & 0.156 & 0.85 & 0.177 & 0.816 \\
\hline 6 & Almusallam et al. & 15 & 0.471 & 1.32 & 0.304 & 0.966 \\
\hline 7 & IRS & 8,20 & 0.571 & 1.36 & 0.337 & 0.815 \\
\hline 8 & Whiffen & [8, 21] & 0.674 & 0.72 & 0.367 & 0.815 \\
\hline 9 & UKAEA & 8,22 & 0.683 & 1.4 & 0.368 & 0.803 \\
\hline 10 & Amman \& Whitney & {$[4,8]$} & 0.692 & 0.71 & 0.372 & 0.803 \\
\hline 11 & Mod. Almusallam et al. & 9 & 0.708 & 1.41 & 0.375 & 0.82 \\
\hline 12 & Mod. NDRC & $4,8,23$ & 0.712 & 1.41 & 0.376 & 0.803 \\
\hline 13 & Young/Sandia & 24 & 0.815 & 0.69 & 0.404 & 0.978 \\
\hline 14 & UMIST & $8,25,26$ & 1.083 & 1.53 & 0.464 & 0.826 \\
\hline 15 & Hwang et al. & [5] & 1.4 & 1.62 & 0.528 & 0.902 \\
\hline 16 & Young & 7 & 1.584 & 1.67 & 0.56 & 0.978 \\
\hline 17 & Berezan & 27 & 1.844 & 1.74 & 0.601 & -0.342 \\
\hline 18 & BRL & [4, 8,28 & 1.989 & 1.78 & 0.629 & 0.821 \\
\hline 19 & Hughes (flexural) & 8,18 & 2.076 & 1.7 & 0.507 & 0.951 \\
\hline 20 & Bergman & [7, 29] & 2.083 & 1.8 & 0.644 & 0.811 \\
\hline 21 & ConWep & 30,31 & 2.32 & 1.86 & 0.679 & 0.803 \\
\hline 22 & Newton & 32 & 2.539 & 1.92 & 0.709 & 0.988 \\
\hline 23 & Zaidi et al. & 33 & 2.559 & 1.92 & 0.713 & 0.82 \\
\hline 24 & British formula & 7, 34 & 2.573 & 1.89 & 0.59 & 0.847 \\
\hline 25 & Tolch \& Bushkovitch & [7, 35] & 3.461 & 2.14 & 0.823 & -0.342 \\
\hline 26 & Mod. Petry I $\left(k=2.26 \cdot 10^{-4}\right)$ & $4,8,36,37$ & 4.006 & 2.26 & 0.885 & -0.344 \\
\hline 27 & TBAA & 7, 38 & 4.782 & 2.44 & 0.975 & 0.827 \\
\hline 28 & Mod. Petry II $\left(K_{\mathrm{p}}=0.01\right)$ & [4, 8, 36, 37] & 5.065 & 2.51 & 0.995 & -0.344 \\
\hline 29 & Hughes (tension) & [8, 18 & 5.794 & 2.67 & 1.069 & 0.699 \\
\hline 30 & Forrestal et al. & [7, 39, 40, & 5.884 & 2.69 & 1.08 & 0.796 \\
\hline 31 & Mod. Forrestal et al. (Teland) & 41 & 6.264 & 2.78 & 1.115 & 0.809 \\
\hline 32 & Li \& Chen & 30,42 & 6.267 & 2.78 & 1.114 & 0.796 \\
\hline 33 & Mod. Forrestal et al. (Frew) & 27 & 6.726 & 2.88 & 1.154 & 0.785 \\
\hline 34 & Mod. Petry I $\left(k=3.39 \cdot 10^{-4}\right)$ & 4,8 & 8.986 & 3.4 & 1.318 & -0.344 \\
\hline 35 & Wen \& Yang & 43 & 17.66 & 0.18 & 1.88 & -0.036 \\
\hline 36 & Adeli \& Amin - cubic & 7, 28 & 102.9 & 64.3 & 154.8 & 0.789 \\
\hline 37 & Adeli \& Amin - quadratic & 7, 28 & - & -19.8 & - & 0.789 \\
\hline 38 & Criepi & [8, 44] & - & 0 & - & 0.795 \\
\hline
\end{tabular}

TABLE 3. Accuracy scale according to logarithmic accuracy assessment with accuracy ratio Qi, logarithmic standard deviation LSD and correlation coefficient values $\rho_{\mathrm{FA}}$ for FMJ-MSC impact.

established use in the penetration prediction in the history and good agreement with experimental results according to other researchers. Modified Hughes equation was added as a representative model since it takes into account tensile strength instead of the unconfined compressive strength.

However, all of the tested models were assembled in an accuracy scale table according to their logarithmic accuracy value from the most accurate to the least accurate, resulting in 36 displayed models (Table 3 ).
The accuracy ratio, LSD and correlation coefficient values were displayed as well as the control quantities.

The modified version of the semi-analytical model, proposed by Hwang et al., was evaluated as a most accurate model in this case. However, the original version of this model turned out to be on the safe side and still displayed sufficient accuracy and is, therefore, preferred to use in engineering practice. The original modified NDRC equation overestimated the results, while the first proposed modification of this equation 


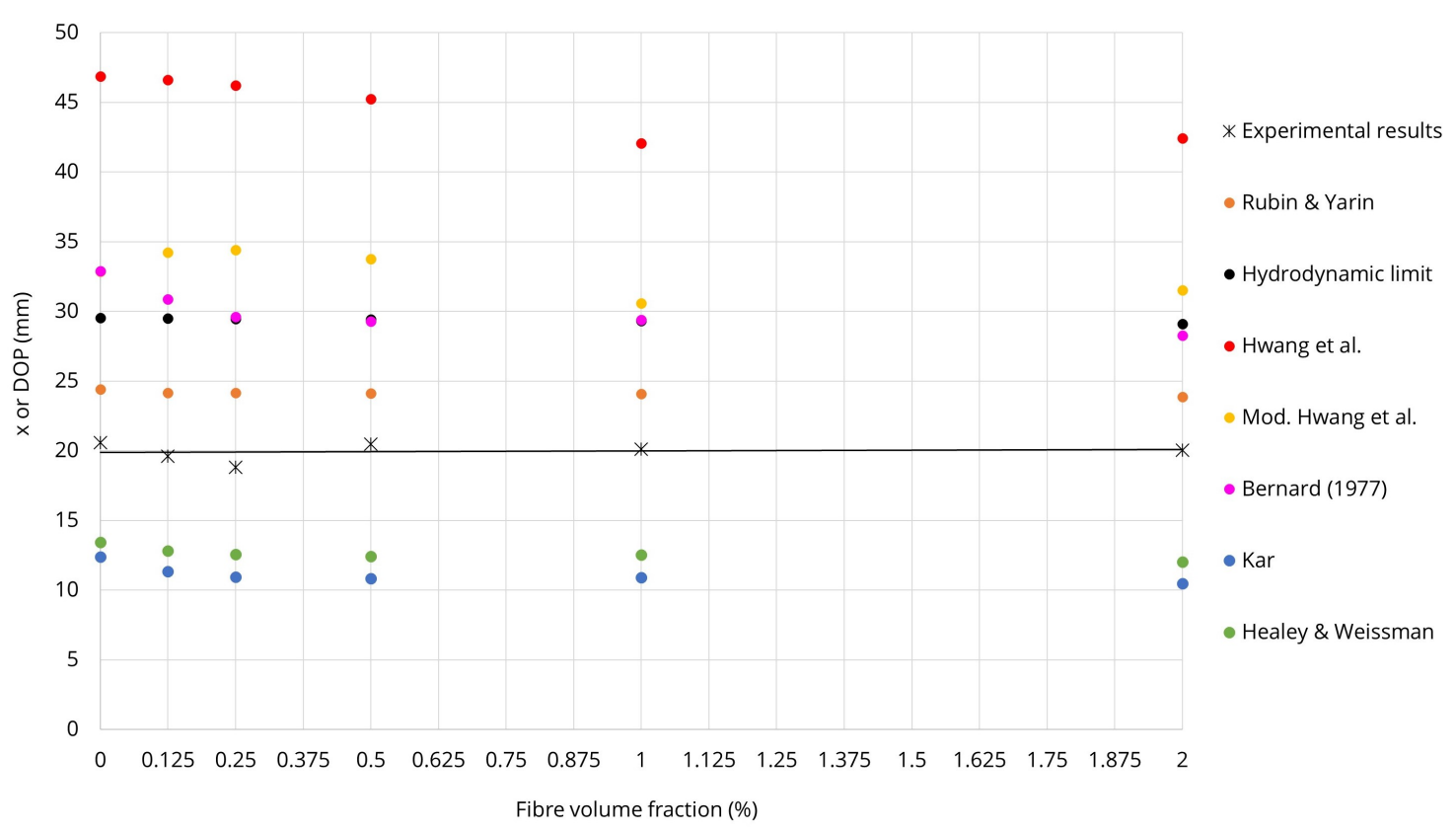

FIgURE 2. Comparison between experimental and representative prediction model results for DOP for FMJ-SLC projectile impact on UHPFRC and linear regression line for experimental data.

by Almusallam et al. adjusted the results with the consideration of fibre volumetric fraction. The modified Hughes equation, where the high strain-rate effect on the tensile strength from the fib model code 2010 [11] was used, turned out to be relatively accurate, however, it underestimated results in the cases of $1 \%$ and $2 \%$ fibre volumetric content.

\subsection{Deformable FMJ-SLC PROJECTILE}

The only models, which take into account projectile deformability, were displayed in this section. The model by Rubin \& Yarin was tested with corresponding material parameters and effective length. In addition, the hydrodynamic limit value 12 was compared with prediction models (Figure2).

Only 10 models were appropriate for the deformable projectile penetration prediction, the other 32 models were developed for a rigid projectile penetration, and were, therefore, labelled as irrelevant (Table 4 ).

The newest and most analytical model by Rubin \& Yarin turned out to be the most accurate, while the hydrodynamic limit provides sufficiently accurate results for this kind of projectile. A model by Hwang et al. and its modified version did provide a good estimation of experimental results. The older models turned out to be less accurate, while the Bernard model from 1977 did provide relatively accurate results on the safe side. The use of Rubin \& Yarin model to the UHPFRC targets yielded a very good agreement to experimental data; however, it is important to note that the Rubin \& Yarin model was originally developed for an eroding projectile penetration into metallic targets. The formula is limited to the case of long-rod penetration where both the projectile and the target experience significant plastic flow. In our case, plastic flow can be expected in the higher volumetric content of fibres in the UHPFRC mixture. Consistently, the prediction is slightly better within the higher volumetric content of fibres (1\% and $2 \%$ ) in the UHPFRC mixture than within lower fibre volumetric fractions. Due to the aforementioned reasons, the use of this model for future predictions on the UHPFRC targets should be cautious.

\section{Results FOR SPALLING MASS EJECTION}

Prediction models values were compared with experimental data, which were transformed from crater volumes values to mass ejection based on the concrete bulk density for each fibre volumetric ratio (Figure 3). Here it must be mentioned that for the evaluation of the model by Abbas et al., the whole projectile diameter was used since it gave a much more realistic description of an actual mass ejection than the core diameter.

\subsection{Non-DEFormable FMJ-MSC PROJECTILE}

It is evident that newly prosed semi-analytical model by Abbas et al. provides much better correlation to the actual mass ejection than the older empirical relation by Sierakowski (Figure 3). The latter is correct in the case of $0.125 \%$ fibre volume fraction; however, this is probably just a coincidental occurrence since the relation was developed for concretes with compressive strengths around $30 \mathrm{MPa}$. Furthermore, it can be seen, that the Sierakowski relation is not following the decrement of the mass ejection values with an increment of fibre volumetric content; 


\begin{tabular}{llccccr}
\hline $\begin{array}{l}\text { Acc. } \\
\text { scale }\end{array}$ & Model & Ref. & $\sum \ln ^{2} Q$ & $Q_{i}$ & $L S D$ & $\rho_{\mathrm{FA}}$ \\
\hline 1 & Rubin \& Yarin & {$[12,41]$} & 0.225 & 1.21 & 0.211 & 0.158 \\
2 & Hydrodynamic limit & {$[41]$} & 0.913 & 1.48 & 0.426 & -0.079 \\
3 & Bernard (1977) & {$[27]$} & 1.022 & 1.51 & 0.448 & 0.266 \\
4 & Healey \& Weissman & {$[\mathbf{8}, 45]$} & 1.261 & 0.63 & 0.503 & 0.213 \\
5 & Mod. Hwang et al.* & {$[5]$} & 1.525 & 1.65 & 0.545 & -0.438 \\
\hline 6 & Bernard (1978) & {$[27]$} & 1.660 & 1.69 & 0.570 & 0.266 \\
7 & Kar & $\mathbf{8 ,}, 45], 46]$ & 2.051 & 0.56 & 0.641 & 0.314 \\
8 & Bernard \& Creighton & {$[27]$} & 2.931 & 2.01 & 0.755 & 0.268 \\
9 & Hwang et al. & {$[5]$} & 3.973 & 2.26 & 0.880 & -0.183 \\
10 & Newton & {$[32]$} & 13.76 & 4.55 & 1.644 & -0.078 \\
\hline & *modified by authors of this study & & & &
\end{tabular}

TABLE 4. Accuracy scale according to logarithmic accuracy estimation with accuracy ratio Qi, logarithmic standard deviation LSD and correlation coefficient values $\rho_{\mathrm{FA}}$ for FMJ-SLC impact.

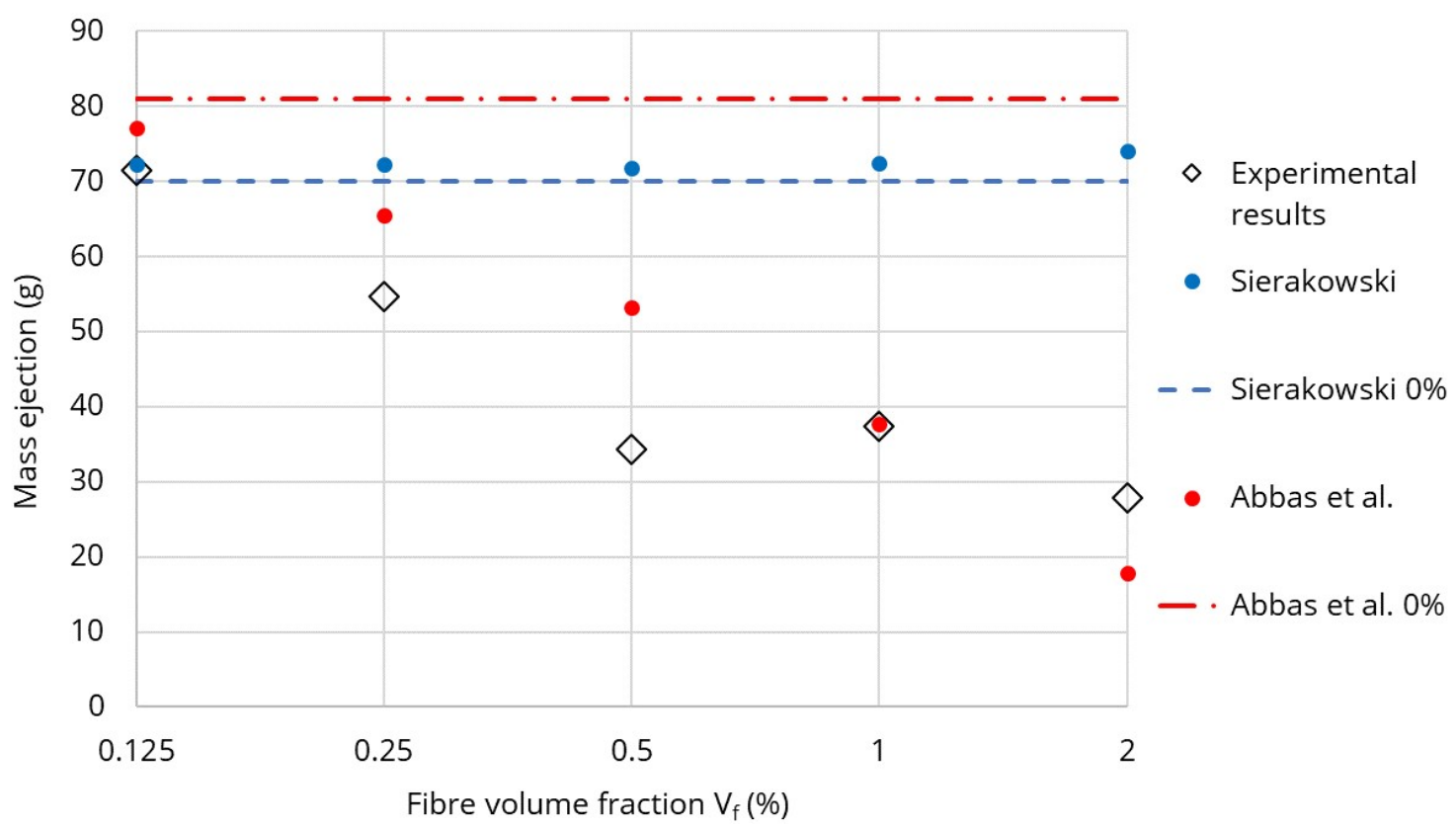

FiguRE 3. Comparison between experimental and prediction models values for mass ejection for FMJ-MSC.

however, the model by Abbas et al. is approximating the experimental values with a sufficient accuracy. The logarithmic accuracy assessment of the latter reached the value of 0.230 , while the correlation coefficient was high: 0.90 .

\subsection{Deformable FMJ-SLC ProjeCtile}

In this case, the term for mass ejection of the cylindrical tunnel in the model by Abbas et al. was not calculated, since it did not appear in the experimental work.

The results are more similar than in the rigid projectile case, since the Sierakowski relation was derived on the supposition of a constant mass, which is only true for the rigid projectile, while the model by Abbas et al. was developed on the basis of the modified NDRC equation, which was not corrected for the use of deformable projectile parameters (Figure 4). The log- arithmic accuracy assessment of the latter was 0.133 , while the correlation coefficient was 0.74 .

\section{Conclusions}

A number of prediction models have been applied in the framework of this study and compared to the experimental readings. It can be deduced that newly proposed and more developed semi-analytical prediction models provide a better fit to the experimental data than older models. It was assessed that the most accurate model for a non-deformable projectile depth of penetration was a model by Hwang et al. with the modified expressions for the cone perimeter and lateral area, while for the deformable projectile, the first place was taken by the model by Rubin \& Yarin. Furthermore, the newer model by Abbas et al. shows a very good agreement with the experimental data for the mass ejection prediction. 


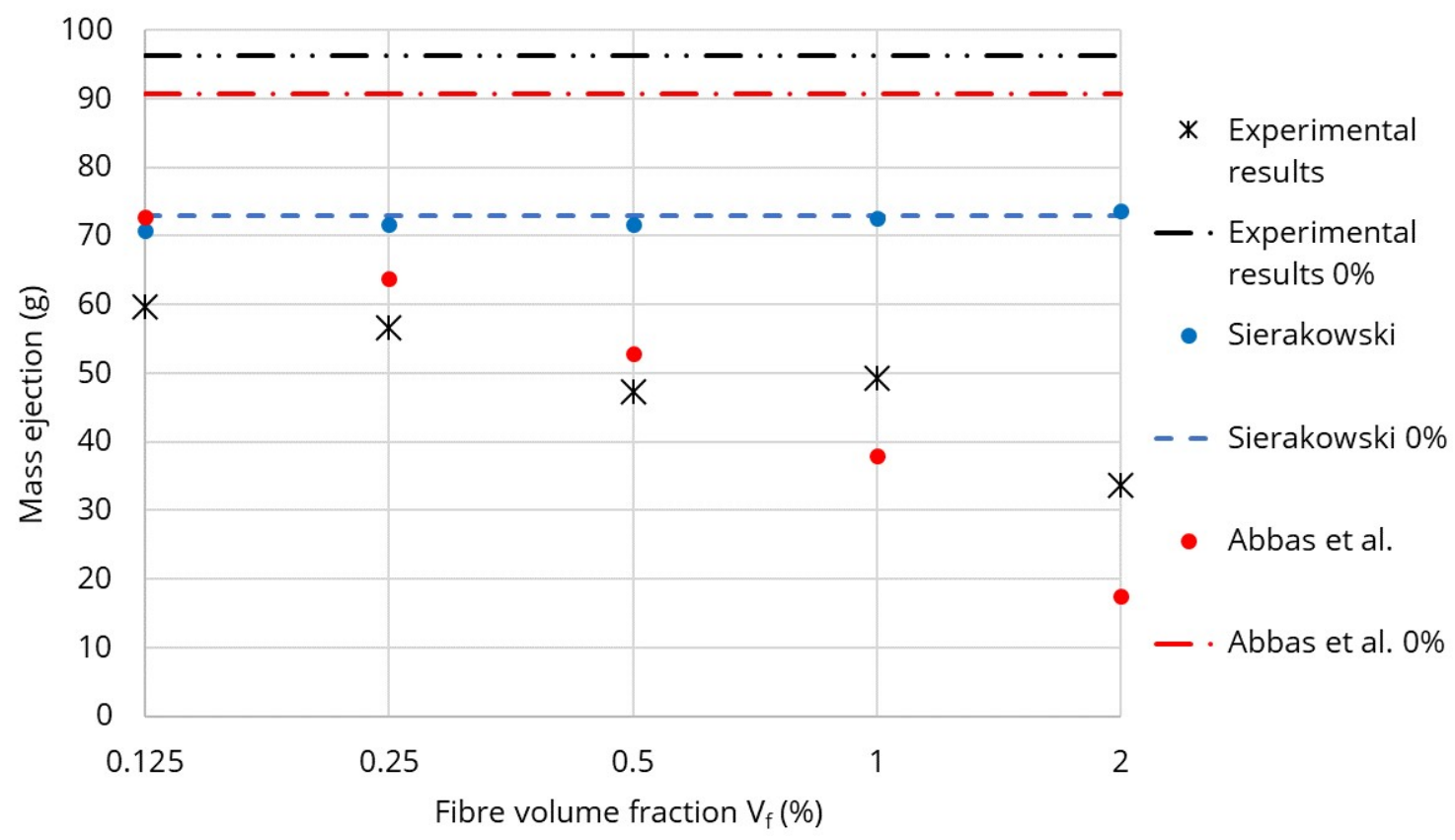

FiguRE 4. Comparison between experimental and prediction models values for mass ejection for FMJ-SLC.

\section{ACKNOWLEDGEMENTS}

This work was supported by the Ministry of Interior of the Czech Republic [project No. VI20172020061]. The authors also acknowledge assistance from the technical staff at the Experimental Centre, Faculty of Civil Engineering, Czech Technical University in Prague; and students who participated in the project.

\section{REFERENCES}

[1] Kravanja S, Sovják R. Ultra-high-performance fibre-reinforced concrete under high-velocity projectile impact. Part I. Experiments. Acta Polytech 2018;58:232-9. DOI:10.14311/AP.2018.58.0232

[2] Tofallis C. A better measure of relative prediction accuracy for model selection and model estimation. J Oper Res Soc 2015;66:1352-62. DOI:10.1057/jors.2014.103

[3] Turk G. Verjetnostni račun in statistika. Delovna Različica Učbenika 2008:VI, 264 pp.

[4] Kennedy RPP. A review of procedures for the analysis and design of concrete structures to resist missile impact effects. Nucl Eng Des 1976;37:183-203. DOI:10.1016/0029-5493(76)90015-7

[5] Hwang H-J, Kim S, Kang T. Prediction of Hard Projectile Penetration on Concrete Targets. 2016 Struct. Congr., Jeju Island, Korea: 2016, p. 1-7.

[6] Yankelevsky DZ. Resistance of a concrete target to penetration of a rigid projectile - revisited. Int J Impact Eng 2017;106:30-43. DOI:10.1016/j.ijimpeng.2017.02.021

[7] Teland JA. A Review of Empirical Equations for Missile Impact Effects on Concrete (FFI/RAPPORT97/05856). Rep FFI/RAPPORT 1997:37.

[8] Li QM, Reid SR, Wen HM, Telford AR. Local impact effects of hard missiles on concrete targets. Int J Impact Eng 2005;32:224-84. DOI:10.1016/j.ijimpeng.2005.04.005
[9] Almusallam TH, Abadel AA, Al-Salloum YA, Siddiqui NA, Abbas H. Effectiveness of hybrid-fibers in improving the impact resistance of RC slabs. Int J Impact Eng 2015;81:61-73. DOI:10.1016/j.ijimpeng.2015.03.010

[10] Song PS, Hwang S. Mechanical properties of high-strength steel fiber-reinforced concrete 2004;18:669-73. DOI:10.1016/j.conbuildmat.2004.04.027

[11] Fédération internationale du béton. Fib model code for concrete structures 2010. 2013.

[12] Rubin MB, Yarin AL. A generalized formula for the penetration depth of a deformable projectile. Int $\mathrm{J}$ Impact Eng 2002;27:387-98. DOI:10.1016/S0734-743X(01)00061-6

[13] Walker JD, Anderson CE. The influence of initial nose shape in eroding penetration. Int J Impact Eng 1994;15:139-48. DOI:10.1016/S0734-743X(05)80027-2

[14] Clifton JR. Penetration Resistance of Concrete - A Review. Washington DC: 1982.

[15] Almusallam TH, Siddiqui NA, Iqbal RA, Abbas H. Response of hybrid-fiber reinforced concrete slabs to hard projectile impact. Int J Impact Eng 2013;58:17-30. DOI:10.1016/j.ijimpeng.2013.02.005

[16] Abbas H, Almusallam T, Al-Salloum Y, Siddiqui N. Prediction of Ejected Mass from Hybrid-Fiber Reinforced Concrete Slabs subjected to Impact Loads. Procedia Eng., vol. 173, 2017, p. 77-84. DOI:10.1016/j.proeng.2016.12.035

[17] Haldar A, Hamieh HA. Local Effect of Solid Missiles on Concrete Structures. J Struct Eng 1984;110:948-60. DOI:10.1061/(ASCE)0733-9445(1984)110:5(948)

[18] Hughes G. Hard missile impact on reinforced concrete. Nucl Eng Des 1984;77:23-35. DOI:10.1016/0029-5493(84)90058-X

[19] Haldar A, Miller FJ. Penetration depth in concrete for nondeformable missiles. Nucl Eng Des 1982;71:79-88. DOI:10.1016/0029-5493(82)90171-6 
[20] Bangash MYH. Impact and explosion: analysis and design. CRC Press; 1993.

[21] Bulson PS. Explosive loading of engineering structures: a history of research and a review of recent developments. E \& FN Spon; 1997.

[22] Barr P. Guidelines for the design and assessment of concrete structures subjected to impact 1987.

[23] Kennedy RP. Effects of an aircraft crash into a concrete reactor containment building. Los Angeles, Calif.: Holmes \& Narver, Inc.; 1966.

[24] Young CW. Penetration equations. Albuquerque, NM, and Livermore, CA (United States): Sandia National Laboratories; 1997. DOI:10.2172/562498

[25] Wen HM, Xian YX. A unified approach for concrete impact. Int J Impact Eng 2015;77:84-96.

[26] UMIST Report ME/AM/02.01/TE/G/018507/Z. Predicting penetration, cone cracking, scabbing and perforation of reinforced concrete targets struck by flat-faced projectiles. 2001.

[27] Ben-Dor G, Dubinsky A, Elperin T. High-Speed Penetration Dynamics: Engineering Models and Methods. World Scientific; 2013. DOI:10.1142/8651

[28] Adeli H, Amin AM. Local effects of impactors on concrete structures. Nucl Eng Des 1985;88:301-17. DOI:10.1016/0029-5493(85)90165-7

[29] Bergman SGA. Intrangning av pansarbrytande projektiler oeh bomber i armerad betong. FortF Rapport B2, Stockholm: 1950.

[30] Wang S, Le HTN, Poh LH, Feng H, Zhang MH. Resistance of high-performance fiber-reinforced cement composites against high-velocity projectile impact. Int J Impact Eng 2016;95:89-104. DOI:10.1016/j.ijimpeng.2016.04.013

[31] ConWep (Conventional Weapons Effects Program). US Army Engineer Waterways Experiment Station. Vicksburg: 1992.

[32] Houghton K, Clark A, Simms H, Kuzemczak J. P3_10 Extinction Event. Phys Spec Top 2012;11.

[33] Zaidi AMA, Bux Q, Rahman IA, Ismail MY. Development of Empirical Prediction Formula for Penetration of Ogive Nose Hard Missile into Concrete Targets. Am J Appl Sci 2010;7:711-6. DOI:10.3844/ajassp.2010.711.716
[34] Vretblad B. Penetration of projectiles in concrete according to FortH 1. Proc. from Work. Weapon Penetration into Hard Targets, Nor. Def. Res. Establ., 1988.

[35] Tolch NA, Bushkovitch AV. Penetration and crater volume in various kinds of rocks as dependent on caliber, mass, and striking velocity of projectile. Ballistic Research Laboratory, Aberdeen Proving Ground, MD: 1947.

[36] Samuely FJ, Hamann CW. Civil protection. The Architectural Press; 1939.

[37] Amirikian A. Design of protective structures. Report NT-3726, Bureau of Yards and Docks, Department of the Navy: 1950.

[38] Fraser RDG. Penetration of projectiles into concrete and soil. n.d.

[39] Forrestal MJ, Altman BS, Cargile JD, Hanchak SJ. An empirical equation for penetration depth of ogivenose projectiles into concrete targets. Int J Impact Eng 1994;15:395-405. DOI:10.1016/0734-743X(94)80024-4

[40] Forrestal MJ, Frew DJ, Hanchak SJ, Brar NS. Penetration of grout and concrete targets with ogive-nose steel projectiles. Int J Impact Eng 1996;18:465-76. DOI:10.1016/0734-743X(95)00048-F

[41] Sjol H, Teland J, Kaldheim O. Penetration into concrete - Analysis of small scale experiments with 12 $\mathrm{mm}$ projectiles. 2002.

[42] Li QM, Chen XW. Dimensionless formulae for penetration depth of concrete target impacted by a non-deformable projectile. Int J Impact Eng 2003;28:93-116. DOI:10.1016/S0734-743X(02)00037-4

[43] Wen HM, Yang Y. A note on the deep penetration of projectiles into concrete. Int J Impact Eng 2014;66:1-4. DOI:10.1016/j.ijimpeng.2013.11.008

[44] Kojima I. An experimental study on local behavior of reinforced concrete slabs to missile impact. Nucl Eng Des 1991;130:121-32. DOI:10.1016/0029-5493(91)90121-W

[45] Bangash MYH. Concrete and concrete structures: numerical modelling and applications. Elsevier Applied Science; 1989.

[46] Kar A. Local Effects of Tornado-Generated Missiles. J Struct Div 1978;104:809-16. 